\title{
Academic Standards and Quality Assurance: The Impact of COVID-19 on University Degree Programs
}

\author{
Kelum A. A. Gamage ${ }^{1, *(\mathbb{D})}$, R. G. G. Roshan Pradeep ${ }^{2}$, Vesna Najdanovic-Visak ${ }^{3}$ (D) \\ and Nanda Gunawardhana 4 \\ 1 James Watt School of Engineering, University of Glasgow, Glasgow G12 8QQ, UK \\ 2 University of Peradeniya, Peradeniya 20400, Sri Lanka; roshan_pradeep268@yahoo.com \\ 3 Chemical Engineering and Applied Chemistry (CEAC), Energy \& Bioproducts Research Institute (EBRI), \\ Aston University, Birmingham B4 7ET, UK; v.najdanovic@aston.ac.uk \\ 4 Learning and Teaching Research Group, Sri Lanka Technological Campus, Padukka 10500, Sri Lanka; \\ nandag@sltc.ac.lk \\ * Correspondence: kelum.gamage@glasgow.ac.uk
}

Received: 30 September 2020; Accepted: 11 November 2020; Published: 1 December 2020

\begin{abstract}
COVID-19, caused by a member of the coronavirus family of viruses, has spread to most countries around the world since it was first recorded in humans in China in late 2019. Closing universities and cancelling all face-to-face activities have become a COVID-19 inevitable reality in many parts of the world. Its impact on university programs, particularly to maintain academic standards and quality assurance procedures, has become significantly more challenging and complex. New ways of working digitally, to minimize disruption to daily operations, have also led to enormous anxiety and uncertainty within the student population, and meeting students' expectations has also become significantly more difficult. This paper reviews actions taken by universities to safeguard high academic standards and quality assurance procedures during this time and appraise the challenges and impacts on students' academic performance.
\end{abstract}

Keywords: assessment of learning outcomes; internal quality assurance; external quality assurance; assessment moderation; accreditation

\section{Introduction}

High academic standards are essential to a university bringing out high-quality research and teaching outcomes, leading to delivery of high-quality graduates. The purpose of maintaining high academic standards can be manifold - not only to meet standards set by the national education standard governing body or professional, statutory and regulatory bodies (PSBR) but to provide confidence to convey that the quality of education meets the current and future competencies and needs of the wider society. According to Anderson et al. (2000), quality assurance is "the means by which an institution is able to confirm that the standards (of teaching and learning), set by the institution itself or other awarding bodies, are being maintained and enhanced" [1]. Consequently, quality assurance (QA) has an important role in monitoring an institution's own processes and performance of achievements, whereby it serves in a consistent application and continuous improvement of processes and reduces the scope for variability. Furthermore, the concepts of quality and standards are interconnected and it is difficult to discuss standards without discussing quality, and vice versa. Quality in higher education is considered in a broad range of inter-related activities, such as curriculum, teaching, student learning, assessment, student experience, student selectivity and research [2]. Because of this multifaceted nature of quality, QA in higher education institutions (HEIs) adopts different approaches 
and procedures. The standards-based approach assesses universities against a set of pre-determined standards, which are often externally developed. The fit-for-purpose approach is used to analyze performance against the internally set goals and missions of the HEI itself. The minimum requirement approach is used to ensure universities fulfil minimum standards, often adopted for compliance purposes [3].

One of the main aims of quality assurance is to identify whether a particular institution fulfils the baseline of the national and/or quality standards set for the higher education institution operations $[4,5]$. Based on the positive results from quality audits that a higher education institution received, they provide the institution with an "authorization" to continue its work. The results of the auditing can be applied, for example, in the marketing of the programs, particularly to attract the best students, as well as in preparing applications for research and development funding. It also allows staff to compare their own university to others on a qualitative scale [6].

Quality assurance procedures can serve two major purposes: accountability and improvement. Quality procedures for accountability are based on criteria aimed at strengthening external insight and control, set by external authorities. Quality assurance for accountability purposes indicates the use of a summative approach, with the possibility of taking corrective actions by an external authority, if necessary. Quality assurance for improvement purposes has a formative approach-the focus is on improving quality instead of control [7].

Universities, being public institutions, have a major responsibility to maintain quality and standards. However, periodic external reviews by an independent agency will provide further credibility to the public and satisfy social accountability. Thus, external quality assurance is considered as an effective way of safeguarding the quality of delivery and standards of awards in higher education while facilitating quality improvement [8]. There can be various agencies inspecting quality in HEIs, such as government bodies (ministries or federal agencies) or autonomous agencies established either by the government or the HEIs themselves [7].

Institutional review analyses and tests the effectiveness of an institution's processes, for managing and assuring the quality of academic activities undertaken by the HEI. It evaluates the extent to which internal quality assurance schemes can be relied upon to maintain the quality of provision of educational programs over time. The overall purpose of an institutional review is to achieve accountability for quality and standards by using a peer review process to promote the sharing of good practices and to facilitate continuous improvement. On the other hand, a Subject/Program review assesses the quality of the student learning experience at the programme level [9].

The designs of higher education quality assurance systems in various countries are influenced by the higher education systems, traditional culture and social backgrounds in that country. Having clearly defined and harmonious relationships of responsibility, rights and interests between various stakeholders in quality assurance is the pre-condition for quality assurance mechanisms to effectively run in these countries [10]. For example, in the UK, the Quality Assurance Agency (QAA) has developed a quality code for higher education, where it enables universities and colleges to understand the expectations of them (see the key elements in Figure 1). Particularly, it helps HEIs to identify quality code as a reference point to protect public and student interests, championing UK higher education's world-leading reputation for quality [11]. 


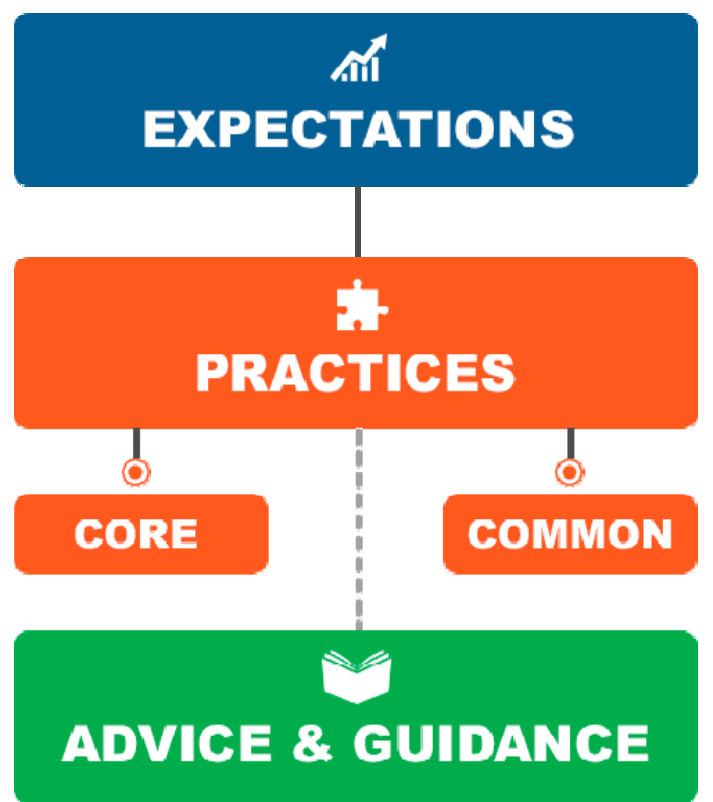

Figure 1. Elements of the quality code as highlighted by the Quality Assurance Agency (QAA), UK [11].

Higher education policies related to quality assurance are instigated in many countries to ensure the provision of high-quality education, university accountability and transparency in using public funding and meeting the needs of the diverse stakeholders [12]. Every university or higher education institution is dedicated to a policy of self-evaluation of all its programs, procedures, services and administrative mechanisms on a regular basis, which encompasses a quality self-assessment. This is because the responsibility for quality and standards in higher education primarily exists within the university itself, rather than outside of it [9].

The novel coronavirus, known as COVID-19, has caused massive disruption to the daily life of humans around the world. On 11 March 2020, the World Health Organization (WHO) declared COVID-19 to be a global pandemic, showing how widely the virus has spread across the world since its first emergence in Wuhan, China, in late 2019 [13]. For an indefinite period, COVID-19 is continuing to raise health concerns and this will continue to challenge many aspects in international higher education as well. As such, the scale of the impact of this pandemic indicates that many HEIs need to adapt and mitigate the consequences.

In what may be termed as a "forced stop", most countries followed a "lockdown" procedure to curtail human movement. Consequently, all face-to-face activities were severely restricted, and universities have had to close down abruptly to ensure that the health and safety of their staff and students are not compromised. According to UNESCO, it is estimated that 1.58 billion learners are off schools, which represents $91.3 \%$ of total enrolled learners in the world [14]. A survey on international student recruitment has also shown that an overwhelming number of prospective students had been impacted by this crisis, causing a change their plans as a result. Most of the respondents have primarily chosen to defer their studies until the following year [15].

Many universities use the conventional education system that requires the physical presence of students and teachers, and therefore, many universities were not fully prepared to face a crisis of such magnitude. Many students have raised issues about travel restrictions, university closure, cancelling of flights, problems in obtaining scholarship interviews, economic collapses, visa applications or language tests, as well exam postponements or cancellations apart from the apparent health concerns [16]. So, at times of crisis, universities must have risk management strategies to maintain their quality and accountability. This paper explores the challenges that universities have encountered as a result of the pandemic and discusses their approaches to retain high academic standards and quality assurance procedures without compromising them. 


\section{Overview of Academic Standards}

\subsection{UK Scenario}

In the UK, before 1992, the primary means of securing quality assurance in universities was dependent upon the system of external examiners. This was a form of peer review with external examiners with the purpose to sustain comparability in degree classifications, and the quality of the teaching and learning process was considered secondary [17]. The Council for National Academic Awards (CNAA) was a national body created in 1964 to approve the degree programs of public sector institutions. Later, with the creation of the Academic Audit Unit (AAU), a more demanding system of quality evaluation was required than that provided by the visits and reports of external examiners. The reviews of the AAU were based on activities of multiple stages, where institutions were required to submit a package of documentation, after which auditors visited the institution to explore issues raised by the documentation and to verify its content. Next, a report was drafted and sent to the institution for comments, which was then followed by a final report [17].

Currently, the quality agenda in England is in a transitional period, with the Quality Assurance Agency (QAA) changing its focus and moving towards quality enhancement. The key components include institutional audit, responsibility for quality at the institutional level and embracing quality enhancement as a cause worthy of promotion rather than as a component of quality assurance while placing more information about the institutional quality and quality procedures in the public domain.

The quality assurance process undertaken by various institutions over time in the UK focused on both institutional audit and departmental inspection. The methodologies involved collection and analysis of institutional data, observation of teaching and interaction with course teams, external examiners, students, alumni and employers etc. Finally, the outcomes of these procedures came out as evaluations (both qualitative and quantitative) and reports for use either internally or publicly [17].

\subsection{Sri Lanka Scenario}

In Sri Lanka (SL), quality assurance is another important area of higher education reforms. Since the late 1970s, policymakers have been debating about the high rate of graduate unemployment and the low quality of graduate output. Quality assurance and accreditation is a recent development in Sri Lanka, carried out by the Quality Assurance and Accreditation Council (QAAC), established in 2005 under the World Bank's Improving Relevance and Quality of Undergraduate Education (IRQUE) project, implemented during 2003-2009. This project provided training, both locally and overseas, for administrative staff of public universities [18]. The first cycle of Institutional and Subject Review was conducted using the Quality Assurance Handbook for Sri Lankan Universities under the administration of the QAA unit of the University Grants Commission (UGC) [9].

Finally, the issue of quality assurance was addressed with the formation of the QAAC in 2005, with funding from the IRQUE project. This led to several new practices, such as the development of subject benchmark statements, subject reviews, external reviews and institutional reviews. The UGC, having recognized the significance of maintaining a good quality of academic output, established the National Quality Assurance and Accreditation Council (NQAAC) as a separate division under its own Secretariat [18].

The main components of this SL QA system are listed below [9]:

1. Sri Lanka Qualification Framework.

2. Subject Benchmarking.

3. Codes of Practice.

4. External Quality Assurance.

5. Internal Quality Assurance. 


\subsection{China Scenario}

The history of QA in HE in China dates back to the 1980s and has expanded progressively in the past few decades. The Chinese government started to introduce QA to HE to ensure education quality in different types of HEIs after the shift of university governance from direct control to supervision combined with the emergence of various new university programs in China [3]. Different approaches of QA were put together to establish a comprehensive framework. The Ministry of Education (MoE) in China combined three quality assessment schemes, quality accreditation, excellence assessment and random assessment, and launched a new project, the Quality Assessment of Undergraduate Education, in 2002. This evaluation consists of three stages: self-examination, expert visit and evaluation and discussion and dissemination of the evaluation results [10].

In undergraduate teaching, evaluation key aspects, such as mission, staff, equipment, program establishment and reform, management, learning environment and outcomes, are inspected on a 5-year rolling cycle at the institutional level. Universities are expected to assess their performance according to the above indicators and submit a report on their achievements, issues and suggestions for improvement. However, the absence of student opinion on these criteria has made it difficult to examine how these QA strategies affect the actual learning experience [3].

\subsection{New Zealand Scenario}

In New Zealand, the quality assurance process is overseen by the Academic Quality Agency for New Zealand Universities (AQA), which focuses on audit cycles on certain constituents of academic quality and the internal processes for monitoring and improving upon them. After a self-study and peer review, the AQA publishes a report with references for improvement, and institutions are held accountable for implementing development plans through progress reports and follow-up reviews [19]. A comprehensive QA framework involves inspection into a number of areas, including mission and purpose, faculty output, instruction, library, laboratory and other physical facilities, administration, etc. [3].

\subsection{Australia Scenario}

Until the 1980s, individual Australian universities were responsible for the development and implementation of quality assurance mechanisms [20]. A review paper from Shah et al. [12] provides a brief history of quality assurance and its evolution in higher education in Australia. Major quality assurance policy in HE initiatives were implemented in 1990s, including Higher Education: Quality and Diversity in the 1990s, to review the discipline approach to quality assurance, a committee for quality assurance in higher education between 1993 and 1995 to review practices and outcomes of public universities and allocation of Quality Assurance and Enhancement operating grants, as well as implementation of the Australian Qualifications Framework (AQF). Further policies were implemented in 2000, namely National Protocols for Higher Education Approval Processes and the Education Service for Overseas Students (ESOS) Act. At the same time, the external agency Australian Universities Quality Agency (AUQA) was formed.

The current Australian higher education quality assurance framework is composed of internal quality management systems (strategic planning, use of key performance indicators, benchmarking, reviews of programs, faculties, schools, students and staff surveys, peer reviews schemes, external examiners, internal moderations, etc.); quality audits by AUQA since 2002, which have resulted in the use of various quality cycles (plan, implement, review and improve approach); government monitoring (performance data and benchmarking with comparable institutions); performance-based funding.

As a result, Australian universities have built an international reputation and good international rankings. 


\section{Assessment of Learning Outcomes and Assessment Regulations/Grading}

Indeed, the outbreak of COVID-19 fundamentally altered the global higher education landscape in 2020. In the space of a few months, it has had a penetrating impact on international student flows, forced HEIs to rethink the use and abilities of online learning platforms and had an impact on a range of other elements within the higher education sector. So, it is clear that switching at least some of the scheduled courses online is the most effective and easily achieved short-term strategy. However, this will also lead to thinking about new ways of assessments and grading for the affected students.

Universities around the world have been forced to significantly restructure assessments. As part of this, some have opted to assess learning outcomes through open-book examinations. To maintain standards, institutions should focus on assessing the same learning outcomes, but this is challenging to achieve. A recent study published by Eurboonyanun et al. [21] compared online medical surgery clerkship assessment scores to the traditional written examinations and concluded that the online open-book examination had a significantly higher mean scores. Although a limited study, this implies that new approaches regarding grading and standard setting are needed to assess long-term knowledge retention and application.

Most HEIs seem to be following a "no detriment" policy. A "no detriment" policy seeks to mitigate against the impact of a set of circumstances by ensuring that an individual is not unfairly disadvantaged by a requirement to change rules or regulations, in session. Thus, for many higher education institutes, "no detriment" means students are guaranteed that their final grade will be no lower than their average academic performance in advance of the pandemic [22]. For example, in some instances, students will not have to sit all of the originally scheduled assessments, so their academic performance to date is being used to determine their grades. In other cases, there will be changes to the assessments-reducing the number or the format of assessments. However, these policies are customary to a particular HEI depending on their student population, academic calendar, pedagogical approaches, curriculum content and assessment systems [22]. The key element here is that a different design of assessment is adopted to achieve the same objective of grading student performance [23].

While highlighting the responsibility of HEIs to protect the academic standard of the qualifications they award, they also have a duty to protect their students' interests in the exceptional situations created by the global pandemic. So, by introducing a "no detriment" (or similar) method, the purpose is to ensure that students are free to focus on their learning and realize their academic goals rather than worrying about risks to their academic outcomes due to problems beyond their control [24].

It is important to note that these measures for current students must not provide undue advantages compared to their peers in previous years and also that they must not be disadvantaged in the future, ensuring that their degree classifications are as reliable as previously.

As such, COVID-19 has caused universities to change their forms of assessment and grading systems drastically. Such approaches include changing the credit volume or workload that students are required to complete to be granted a qualification, providing them only with pass/fail instead of a grade, making minor amendments to allow students to progress and achieve the "missing" learning objectives later, allow reattempts to failed students without an academic penalty or evidence of exceptional circumstances, allowing students to progress by considering their average grades across the required credits to reach a pass of $40 \%$, alternative assessment formats (e.g., "open-book exams"), calculating a final module grade if all assessments cannot be completed provided that the learning outcomes had been achieved from the already-completed assessment(s) by the student and, finally, in extreme cases, making changes to the degree algorithms and classification profiles [22,25].

Although there are many instances where these approaches could be successfully (at least to a great extent) implemented, for subject areas such as clinical medicine, performing arts and science-based disciplines, which involve laboratory and field activities—which require psychomotor skills and competence in using or handling equipment—-this will not be pragmatic enough, since the learning outcomes cannot be met without in-house training. Further, it must be highlighted that any of these 
changes must be effectively communicated to the students, and it is also important that the opinions of students must also be considered before implementing such changes.

Some typical examples [26]:

At Western Sydney University, Australia, the assessments will be graded as previously using the traditional approach, but students will have the option of choosing to have the final passing grade converted to a non-graded pass. These non-graded passes would not count towards the students' final grade point average. Similarly, the University of Melbourne has decided to retain its usual percentage marks for courses undertaken by students this semester but has noted that students' grade percentage distributions will be examined to evaluate whether universal changes to the calculation of grades are necessary. However, the University of Sydney has introduced three new grade options, Discontinued (DC), Result Incomplete (RI) or UC Grade, when a unit of study follows on to another and a series of mark adjustments by adopting a "no-disadvantage assessment" position, which they recognize as a transparent, just and supporting academic progression.

There is also a "special consideration" situation identified by most universities in order to address issues where students experience short-term circumstances, e.g., illness, injury or misadventure, which can substantially affect their preparation or performance in an assessment. In such instances, the students can either complete a "declaration form" with any available supporting evidence so that they will not be disadvantaged due to events beyond their control. In addition, special attention is also been given for instances such as students with disabilities and cases where students act as caretakers of persons affected by COVID-19 within the family, or students working in the healthcare system.

\section{Internal Quality Assurance}

\subsection{Internal Moderation}

According to the definition of the Internal Quality Assurance Manual for Sri Lankan Universities [8], internal quality assurance refers to "internal processes that an institution has developed in order to monitor and improve the quality of their students' learning experience and ensure achievement of established goals, objectives and standards". This shows that this needs to be a continuous, ongoing process where everyone working in an institution must take responsibility to incorporate it into their day-to-day, activities. Therefore, internal QA can be considered as the keystone of QA in higher education.

Areas that are considered of particular importance in internal quality assurance include policy and procedures for higher education; approval, monitoring and periodic review of programs and awards; assessment of students; quality assurance of teaching staff; learning resources and student support; information systems; public information [27].

Due to COVID-19, new challenges have led universities to rethink their QA procedures. According to a recent survey, with respect to crisis management, most universities have highlighted the importance of the following factors [16]:

- Online learning.

- International coordination and collaboration.

- Strong university leadership.

- Proactive, preventative measures.

- Flexibility for assessment deadlines and exams.

- Stricter sanitation initiatives.

- Clear communication from university leadership and administrators.

Due to COVID-19, there is a chance that these aspects must also be considered into evaluation criteria during the review process.

An important part of QA involves learning about the student experience, but now, obtaining student feedback is compromised due to social distancing, as are organized site visits. 
Preparation of reports needs data collection and finding suitable stakeholders to collect, analyze/review and interpret data is needed. Using new software/cloud and web-based platforms and technology to meet online, add data online or simply to defer until things turn normal or even in extreme cases, QA procedures can be judged by looking at achievements and performances in the recent past.

The need to use electronic and online cloud-based platforms is stressed. With holding committee meetings via Zoom or Teams, both web conferencing apps, accessibility (internet or compatible computer technology) and technical literacy are some limitations that need to be addressed, as well as difficulties in coming together as groups for committee discussions and getting used to working while at home (e.g., finding quiet, dedicated office spaces at home).

Finding data or answering questions in QA processes is easy (especially in pandemic situations) if there is a management information system (MIS) and electronic databases, but in countries such as Sri Lanka, where they are implemented at low levels in most universities, it will be very difficult, as these data must be physically accessed by looking at hard copies (paper-based records).

Performing internal quality audits was initially the QA system of universities, even in the UK. Preparation of internal quality reports involved the participation of many personnel at various hierarchies of the university (faculty, departments, administrative, etc.). Due to the COVID-19 scenario, such activities are limited or must be carried out while obeying the social distancing health guidelines.

\subsection{External Quality Assurance}

As mentioned earlier, internal quality assurance is supported by periodic external review. The two processes have to be harmonized for maximum benefit. External quality assurance (EQA) or review is an important component of the QA framework. Its main aims are to safeguard standards of awards and quality of delivery in higher education; to identify good practices; to facilitate continuous quality improvement; to inculcate the quality culture into the higher education system [9]. HEIs must make a deliberate effort to address any shortcomings of these internal and external reviews and implement any other suggestions and recommendations [28].

External examiners are integral to a system of evaluation as they focus more on professional and disciplinary values rather than the institutional authority to endure quality in higher education [17]. According to European standards, it is recommended that external quality assurance procedures should take into account the effectiveness of such internal quality assurance processes [7]. From this, it is seen that this external review is now a critical element that has become an internationally accepted aspect of quality assurance [29]. Identification of the criteria used for external quality assurance can enlighten institutions in helping to identify which internal processes are working well and those that need to be strengthened further.

The main features of EQA irrespective of the unit of assessment are self-evaluation by the institution/programme, peer review including a review visit and perusal of evidence culminating in a review report with judgement and commentary $[9,29]$.

In the preparation phase, the institution will have to begin compiling its self-evaluation document several months before the visit and submit it in advance to the review team. At the other end, the review team will meet either to fully understand the document or to plan their detailed inquiries to identify lines of inquiry. They will also identify individuals and groups they wish to meet during the visit. In the second phase, the review team will visit to examine and verify the claims in the university's self-evaluation. This will include an evaluation with the university of any specific concerns arising from reviews done before the visit, gathering further evidence to evaluate the effectiveness of the institution's arrangements for the management of quality and standards and, finally, assessing the extent to which recommendations and disparagements made by the previous reviews have been addressed. The outcome of the institutional review is a published report. This report will give an overall finding on the reviewer's evaluation of the performance of the institution to provide a reference point to support and guide staff in their continuing quality assurance activities [9,29]. 
The review team will also consult the documentation provided by the institution. The aim is to reflect on evidence provided by the institution and to focus on discussions with staff and students to get a clear picture of the institution's processes in operation. Most evidence for review will come from information and documentation used by the institution itself. Therefore, the self-evaluation report (SER) of the university becomes a key document both for itself and the review team. A careful and succinct SER, while helping the university to recognize its own strengths and weaknesses, also helps the review team to plan its review process more effectively and efficiently $[9,28]$.

The review visit, under normal circumstances, takes up to five days, depending on the number of sites, diversity of provision and clarity and depth of the university's self-evaluation report. The visits usually conclude with a meeting with the Vice Chancellor and senior staff.

Due to COVID-19, there are new concerns with students regarding safety at the HEI, their future studies, learning resources and student support, assessments, etc., which have to be addressed in the report. For HEIs freshly participating in QA activities, it is best to defer the activities, as the self-evaluation report needs lots of information collection and analysis. There will also be implications in how to hold training sessions for preparing reports, training for evaluations, scheduling meetings, adherence to previous quality parameters, or perhaps changing them, and the effectiveness of the university's/HEI's processes.

The Beijing Institute of Technology introduced a "higher education monitoring evaluation", a new higher education quality assessment technology that uses modern information technology to frequently collect relevant data and visually present the status of higher education, providing an objective basis for value judgments and scientific decision-making [10]. This monitoring evaluation is a data-intensive evaluation, aiming to provide and promote feedback for continuous quality improvement, to follow the systematic change of higher education for scientific decision-making and to deliver user-oriented information service for diverse value judgments. The technology of higher education monitoring evaluation includes data collection and consolidation, data mining and analysis and data visualization.

Accreditation is a process where an institution's services and operations are examined by an external accrediting agency to determine if applicable standards are met. If they are met, the institution receives accreditation. Accreditation creates confidence and trust in the quality of the HEI and its programs and awards students, parents, prospective employers and the general public while giving international recognition $[9,28]$. It serves as a sign of the HEI's adequacy in five aspects, including academic quality, value for money, efficiency and effectiveness, student protection and transparency [9]. One of the most important benefits of program accreditation is recognition at the international level. This can be applied in international marketing of degree programs as well as in international collaboration-for example, in the double-degree cooperation with international partner higher education institutions [6].

Relevant professional accreditation bodies usually prescribe the number of hours for laboratory or field-based activities in a degree. Delivery of these activities can be jeopardized due to social distancing health guidelines. Therefore, it is of utmost importance for HEIs to enter into dialogue with professional bodies to adjust delivery and assessment approaches. According to the COVID-19 guidance on academic standards published by QAA [30], some HEIs have reported some resistance to certain models, but many have worked closely with HEIs and supported them in their efforts.

Universities aim to maintain overall standards and to mitigate negative impacts on the students' overall outcomes by making various adjustments, including the use of video demonstrations, virtual labs software, artificial intelligence, etc. However, the implementation of these adjustments is limited due to the very short notice under which universities are also required to protect the health, welfare and safety of students and staff or to follow the advice of local or national authorities. Therefore, the development of a robust provision to deliver remote access to laboratories and observatories is a huge challenge for most universities, requiring time, effort and considerable investments. 


\section{Academic Integrity}

The International Center for Academic Integrity (ICAI) defines Academic Integrity as 'a commitment, even in the face of adversity, to six fundamental values: honesty, trust, fairness, respect, responsibility, and courage [31]. From these values flow principles of behaviour that enable academic communities to translate ideals to action'. As such, academic integrity is a concept which, on one hand, protects the quality of the student learning experience, to value their academic achievements, and, on the other hand, provides assurance and reputation for the higher education institutions for the programs offered. Hence, it can be understood that sustaining academic integrity has a two-way approach: (1) prevent and act against academic misconduct and (2) popularize good practices [31]. It is important to note that academic integrity must be maintained at all times, irrespective of global pandemics; the only thing is that the measures to secure it will depend on how the learning outcomes of a programme are assessed by the higher education institution. It is the responsibility of the higher education institution to remind students of the policies already put in place on academic integrity and highlight that these continue to apply even in the current circumstances.

As a consequence of COVID-19, higher education institutions have had to adjust their assessment practices to suit online delivery. In doing so, it must be ensured that these practices are robust, safeguarding against academic misconduct but equally ensuring fairness for students who have had to sit for university assessments during challenging circumstances.

All stakeholders of the academic community (e.g., academia, students, professional services, administration and the management) need to be aware of policies, procedures, regulations, expectations and sanctions, as well as to be supported to understand what academic practices are considered as acceptable or not.

Furthermore, it is essential to ensure that students are aware of the potential consequences if they are caught cheating. In order to convey this effectively, discussing academic misconduct with students and the risks involved will help them understand the long-term and ethical benefits of the genuineness of their work [32]. Some further actions involve developing internal networks of academic integrity support or submitting an "Academic Integrity Honesty Statement" or equivalent for students before they sit for online exams to make them personally responsible by putting their signature [33].

\subsection{How to Uphold Academic Integrity in Online Delivery: Course/Lab/Assessment Design}

In the UK, for example, as suggested by QAA guidelines/National Forum Enhancement Theme, some actions include preparing students with skills, such as academic writing and referencing skills, necessary to succeed in their assessments; frameworks and structures to keep students on track; moderation of peer learning forums and other student-friendly channels to communicate university support; proper dealing with cases of misconduct; consider accessibility to all students (hardware/software requirements, assessment submission processes, logistical issues, etc.) in using technology and engaging with online assessment tools [34].

\subsection{Use of Technology: Plagiarism Checker, Virtual Invigilation}

The use of technology to curb this issue is seen as a potential solution in the ever-evolving methods of compromising academic honesty and integrity. Apart from blocking access to "essay mills" and disrupting their advertising tactics on university IT systems, modifying online assessments is also important to discourage the students from cheating [35].

Online proctoring services, for example (which use a combination of microphone, webcam, speakers, screen-sharing, etc.), can be used to supervise remote exams. For these purposes, a specialist online testing service (such as ProctorU) can be utilized, which operates under multi-jurisdictional privacy and security regulations while ensuring that student privacy and security is safeguarded during online invigilation [36]. It is worth mentioning, here, the challenges related to the large-scale move to online assessments, e.g., cost, capability, risks, etc. 
In the context of essays and other written assignments, modifying assessments to allow students to demonstrate their skills (combining straight answer questions with brief explanations or reasoning) can also help them to develop deep learning abilities [35]. Use of software (plagiarism checking, text matching, stylometric and linguistic analytics, etc.) is also a recommended technique [29]. If written assignments can be completed in a student's own time, students can be provided with early drafts or "checkpoints" as these assignments are more prone to cheating [34]. This "checkpoints" or ("advanced drafts") method can be used for assessing group activities as well. Additionally, calling students after submission of assignments for a brief online 'viva' to check their understanding and authenticity of the work and comparing previous student performances to what has been obtained via online assessments to determine whether it keeps with expectations can also help in maintaining the integrity of written essays [25]. For individual or group performances (performance arts such as music, dance, drama, etc.), alternative assessments, such as video/audio recordings, recitals, online portfolios and virtual studios, and written assessments, such as essays, reflective blogs, etc., can be used [37]. However, these assessments must, in one way, be achievable for students at home while also being assessable for home-working teachers/markers.

\section{Safety}

The COVID-19 situation has forced HEIs to amend existing processes in order to open campuses for students and staff following public health advice and government rules on social distancing. This is of particular importance for programs involving heavy elements of practical work. This academic year, many universities have adopted a blended approach that combines both online and on-campus teaching. Usually, on-campus teaching activities involve tutorials and practicals, while large-scale lectures are being delivered using online technology. Another interesting approach is to use a dual-mode system that delivers material simultaneously for on-campus face-to-face students and off-campus online students. The Chemical Engineering and Applied Chemistry Department at Aston University has recently adopted dual-mode teaching for practicals and workshops, providing students with additional flexibility to switch between the face-to-face and online modes but also allowing adequate social distancing on campus.

It is clear that university programs have been adapting their teaching settings and contexts due to the safety requirements imposed by the COVID-19 pandemic. Recently, Universities UK has published a list of principles for individual universities to deliver their teaching safely and in line with guidance from governments, public health advice and health and safety legislation [38]. These include health, safety and wellbeing, changes to university layout and infrastructure, reviews of teaching, learning and assessment, review of the welfare and mental health needs of students and staff, support for international students and staff, review of cleaning protocols and risk assessments as well as engagement with the wider community, such as trade unions, councils and other community groups.

To conclude, health guidelines have become a new part of the teaching, learning and assessment planning, placing themselves as a central part of quality assurance in HEIs.

\section{Conclusions}

Quality assurance exercises need a good set of information on pre-determined criteria and standards to sustain quality judgments. An internal quality assurance procedure with the preparation of a self-assessment report is a core element of the external quality assurance process. Identification of the criteria used for external quality assurance can inform institutions of what they need to focus on for developing and strengthening their internal quality assurance processes. Due to COVID-19, new challenges have led universities to rethink their IQA and EQA procedures, struggling to navigate this crisis while maintaining consistent course delivery, ensuring strong student recruitment and providing clear communication to staff and students.

As such, the scale of the impact of this pandemic has forced many HEIs to adapt and take effective actions to mitigate the undue consequences of crises. This paper highlights several important 
challenges to safeguard high academic standards. Assessments have been moved to open-book examinations in order to assess learning outcomes, which brings the need for different grading and standard settings, particularly for programs with heavy practical components. Robust provision and delivery of remote access to laboratories and observatories is of utmost importance for both students' learning and quality assurance processes, but their development requires time, effort and considerable investments. Issues related to academic integrity have also been addressed, namely the importance of academic writing and referencing training, online proctoring services and alternative assessments, such as "check-points" and vivas.

Finally, the safety of students and staff and their well-being will be central to addressing the highlighted issues. So, there is a new question to quality assurance in higher education: Will health guidelines become a new part of QA for the good of humankind in pandemic situations?

Author Contributions: Conceptualization, K.A.A.G.; methodology, K.A.A.G. and R.G.G.R.P.; formal analysis, R.G.G.R.P.; investigation, R.G.G.R.P.; resources, N.G.; writing—original draft preparation, R.G.G.R.P., K.A.A.G. and V.N.-V.; writing-review and editing, K.A.A.G. and V.N.-V.; supervision, K.A.A.G.; project administration, K.A.A.G. and N.G. All authors have read and agreed to the published version of the manuscript.

Funding: This research was partly funded by seed funding from Sri Lanka Technological Campus, Sri Lanka.

Conflicts of Interest: The authors declare no conflict of interest.

\section{References}

1. Anderson, D.; Johnson, R.; Milligan, B. Quality Assurance and Accreditation in Australian Higher Education: An Assessment of Australian and International Practice, 1st ed.; AusInfo: Canberra, Australia, 2000.

2. Thompson-Whiteside, S. Assessing academic standards in Australian higher education. In Tertiary Education Policy in Australia, 1st ed.; Marginson, S., Ed.; Centre for the Study of Higher Education, University of Melbourne: Melbourne, Australia, 2013; Chapter 5; pp. 39-48.

3. Wang, L. Quality assurance in higher education in China: Control, accountability and freedom. Policy Soc. 2014, 33, 253-262. [CrossRef]

4. Ellis, R. Quality assurance for university teaching: Issues and approaches. In Quality Assurance for University Teaching, 1st ed.; Ellis, R., Ed.; Taylor \& Francis: Bristol, UK; pp. 3-15.

5. Ellis, R. Quality assurance for university teaching. In Handbook of Quality Assurance for University Teaching, 1st ed.; Ellis, R., Hogard, E., Eds.; Taylor \& Francis: London, UK; pp. 3-18.

6. Bejan, S.A.; Janatuinen, T.; Jurvelin, J.; Klöpping, S.; Malinen, H.; Minke, B.; Vacareanu, R. Quality assurance and its impact from higher education institutions' perspectives: Methodological approaches, experiences and expectations. Qual. High. Educ. 2015, 21, 343-371. [CrossRef]

7. Kis, V. Quality Assurance in Tertiary Education: Current Practices in OECD Countries and a Literature Review on Potential Effects. OECD (2005), Thematic Review of Tertiary Education. Available online: http://www.oecd.org/education/skills-beyond-school/38006910.pdf (accessed on 25 September 2020).

8. Coomaraswamy, U.; Jayatilleke, G.; Abeygunawardena, H. Manual for Quality Assurance of External Degree Programmes and Extension Courses Offered by Universities, 1st ed.; University Grants Commission: Colombo, Sri Lanka, 2014; Chapter 4; pp. 57-70.

9. Warnasuriya, N.; Coomaraswamy, U.; de Silva, N.; Nandadeva, B.D.; Abeygunawardena, H. Higher education for the twenty first century (HETC) project ministry of higher education and research. In Manual for Institutional Review of Sri Lankan Universities and Higher Education Institutions, 1st ed.; Sri Lanka \& University Grants Commission: Colombo, Sri Lanka, 2015; Chapter 2; pp. 21-27.

10. Shuiyun, L. External Higher Education Quality Assurance System in China, Chinese Education \& Society. Chin. Educ. Soc. 2016, 49, 1-6.

11. Quality Assurance Agency (QAA). The Revised UK Quality Code for Higher Education; UK Standing Committee for Quality Assessment: Gloucester, UK, 2018.

12. Shah, M.; Nair, S.; Wilson, M. Quality assurance in Australian higher education: Historical and future development. Asia Pac. Educ. Rev. 2011, 12, 475-483. [CrossRef] 
13. World Health Organization. WHO Director-General's Opening Remarks at the Media Briefing on COVID-19-11 March 2020. Available online: https://www.who.int/dg/speeches/detail/who-director-generals-opening-remarks-at-the-media-briefing-on-covid-19---11-march-2020 (accessed on 28 September 2020).

14. UNESCO. Education: From Disruption to Recovery. Available online: https://en.unesco.org/covid19/ educationresponse (accessed on 28 September 2020).

15. QS Quacquarelli Symonds. How COVID-19 is Impacting Prospective International Students across the Globe. Available online: https:/www.qs.com/portfolio-items/how-covid-19-is-impacting-prospective-internationalstudents-across-the-globe/ (accessed on 28 September 2020).

16. QS Quacquarelli Symonds. The Impact of the Coronavirus on Global Higher Education. Available online: https:/www.qs.com/portfolio-items/the-impact-of-the-coronavirus-on-global-highereducation/ (accessed on 28 September 2020).

17. Filippakou, O.; Tapper, T. Quality Assurance in Higher Education: Thinking beyond the English Experience. High. Educ. Policy 2007, 20, 339-360. [CrossRef]

18. Asian Development Bank. Innovative Strategies for Accelerated Human Resource Development in South Asia, 1st ed.; Asian Development Bank: Mandaluyong City, Philippines, 2016; pp. 27-53.

19. Brown, J.; Kurzweil, M.; Pritchett, W. Quality Assurance in U.S. Higher Education-The Current Landscape and Principles for Reform, 1st ed.; Ithaka: New York City, NY, USA, 2017; pp. 23-26.

20. Mikol, M. Quality Assurance in Australian Higher Education: A Case Study of the University of Western Sydney (Nepean); University of Western Sydney: Sydney, Australia, 1996.

21. Eurboonyanun, C.; Wittayapairoch, J.; Aphinives, P.; Petrusa, E.; Gee, D.W.; Phitayakorn, R. Adaptation to Open-Book Online Examination during the COVID-19 Pandemic. J. Surg. Educ. 2020, in press. [CrossRef] [PubMed]

22. The Quality Assurance Agency for Higher Education. 'No Detriment' Policies: An Overview. 2020. Available online: https://www.qaa.ac.uk/docs/qaa/guidance/no-detriment-policies-an-overview.pdf (accessed on 28 September 2020).

23. University College Dublin. Guidance for Designing Alternative Assessment Methods: COVID 19 Contingency Planning. 2020. Available online: https://www.ucd.ie/teaching/t4media/alternative_assessment_methods.pdf (accessed on 28 September 2020).

24. T\&L National Forum for the Enhancement of Teaching and Learning in Higher Education. Available online: https://www.teachingandlearning.ie/wp-content/uploads/Assessment-methods-resourcefor-publication-final.pdf (accessed on 28 September 2020).

25. The Quality Assurance Agency for Higher Education. COVID-19: Thematic Guidance-Securing Academic Standards and Supporting Student Achievement. 2020. Available online: https://www.qaa.ac.uk/ docs/qaa/guidance/covid-19-thematic-guidance-academic-standards.pdf?sfvrsn=cbcccd81_6 (accessed on 28 September 2020).

26. The Quality Assurance Agency for Higher Education. International Examples of Practice in Response to the COVID-19 Pandemic: An Overview. 2020. Available online: https://www.qaa.ac.uk/docs/qaa/guidance/ international-examples-of-practice-covid-19.pdf?sfvrsn=b3aecd81_2 (accessed on 28 September 2020).

27. European Network for Quality Assurance in Higher Education (ENQA). Report on Standards and Guidelines for Quality Assurance in the European Higher Education Area, 3rd ed.; European Association for Quality Assurance in Higher Education: Helsinki, Finland, 2009; pp. 16-19.

28. Coomaraswamy, U.; Abeygunawardena, H. Quality assurance and accreditation of undergraduate and postgraduate degree programmes. In Proceedings of the Re-creating and Re-positioning of Sri Lankan Universities to meet Emerging Opportunities and Challenges in a Globalized Environment, Kalutara, Sri Lanka, 18-19 June 2012; Senaratne, R., Sivasegaram, S., Eds.; University Grants Commission and Ministry of Higher Education: Colombo, Sri Lanka, 2012; pp. 181-200.

29. Martin, M.; Stella, A. Conducting the Process of External Quality Assurance, 1st ed.; International Institute for Educational Planning (UNESCO): Paris, France, 2010; pp. 10-12.

30. The Quality Assurance Agency for Higher Education. Preserving Quality and Standards through a Time of Rapid Change: UK Higher Education in 2020-21. 2020. Available online: https://www.qaa.ac. uk/docs/qaa/guidance/preserving-quality-and-standards-through-a-time-of-rapid-change.pdf (accessed on 6 November 2020). 
31. Bretag, T. Handbook of Academic Integrity, 1st ed.; Springer Science + Business Media: Singapore, 2016; pp. 3-22.

32. The Quality Assurance Agency for Higher Education. Assessing with Integrity in Digital Delivery. 2020. Available online: https://www.qaa.ac.uk/docs/qaa/guidance/assessing-with-integrity-in-digital-delivery.pdf (accessed on 28 September 2020).

33. The University of Waterloo. Confidentiality Agreement \& Statement of Honesty. Available online: https: //uwaterloo.ca/academic-integrity/sites/ca.academic-integrity/files/uploads/files/honour_statement.pdf (accessed on 28 September 2020).

34. The Quality Assurance Agency for Higher Education. Contacting to Cheat in Higher Education: How to Address Essay Mills and Contract Cheating. 2017. Available online: https://www.qaa.ac.uk/docs/qaa/ guidance/contracting-to-cheat-in-higher-education-2nd-edition.pdf (accessed on 28 September 2020).

35. Deakin University. Available online: http://wordpress-ms.deakin.edu.au/dteach/wp-content/uploads/sites/ 103/2020/03/DigitalExamsAssessmentGuide1.pdf?_ga=2.217745174.1869770854.1601470891-1753161286. 1601470891 (accessed on 28 September 2020).

36. UC SanDiego. Available online: https://myemail.constantcontact.com/Moving-to-Remote-Assessmentswith-Integrity.html?soid=1129123483094\&aid=9byY06J_J9s (accessed on 28 September 2020).

37. The Quality Assurance Agency for Higher Education. COVID-19: Thematic Guidance-Practice and Lab-based Assessment. 2017. Available online: https:/www.qaa.ac.uk/docs/qaa/guidance/covid-19-thematicguidance-practice-lab-based-assessment.pdf?sfvrsn=f3cccd81_6 (accessed on 29 September 2020).

38. Universities UK. 2020. Available online: https:/www.universitiesuk.ac.uk/policy-and-analysis/reports/ Documents/2020/principles-and-considerations-emerging-from-lockdown-june-2020.pdf (accessed on 6 September 2020).

Publisher's Note: MDPI stays neutral with regard to jurisdictional claims in published maps and institutional affiliations. 